\title{
BMI gain and insulin resistance among school-aged children: a population-based longitudinal study in the Brazilian Amazon
}

\author{
Barbara H. Lourenço ${ }^{1}$, Suely G. A. Gimeno ${ }^{2}$ and Marly A. Cardoso ${ }^{3 *}$ for the ACTION Study Team \\ ${ }^{1}$ Public Health Nutrition Program, School of Public Health, University of São Paulo, São Paulo, Brazil \\ ${ }^{2}$ Department of Preventive Medicine, Federal University of São Paulo, São Paulo, Brazil \\ ${ }^{3}$ Department of Nutrition, School of Public Health, University of São Paulo, Avenida Dr Arnaldo 715, São Paulo, \\ SP 01246-904, Brazil \\ (Submitted 24 June 2014 - Final revision received 30 July 2014 - Accepted 7 August 2014 - First published online 8 October 2014)
}

\section{Abstract}

Investigation of the determinants of metabolic outcomes associated with non-communicable diseases is increasingly important in developing countries, but such parameters have not been explored extensively during childhood. The present study assessed the impact of weight gain, measured as BMI-for-age $Z$-scores, on glucose and insulin concentrations, homeostasis model assessment index of insulin resistance (HOMA-IR) values, and systolic and diastolic blood pressure during school years among Amazonian children. A populationbased prospective study of 696 children aged $>4$ to $\leq 10$ years with complete anthropometric information at baseline $(51 \%$ females and $86 \%$ of mixed race) was carried out; 411 children had data on metabolic parameters after a median follow-up period of $2 \cdot 0$ years (range 1.7-2.6 years). During follow-up, there was a significant increase in the proportion of overweight children (BMI-for-age $Z$-score $>1)$ from $10 \cdot 1$ to $15 \cdot 8 \%(P=0 \cdot 003)$. In linear regression models adjusted for the child's sex, age, race/ethnicity, baseline household wealth, birth weight and pubertal development stage, for each unit of BMI-for-age $Z$-score variation during follow-up, an increase of $8.58(95 \%$ CI $7.68,9.60) \mathrm{pmol} / 1$ in fasting plasma insulin concentrations and 1.47 (95\% CI 1.30, 1.66) in HOMA-IR values was observed. There was no significant impact of weight gain on glucose concentrations and systolic and diastolic blood pressure. In conclusion, we found evidence that an increase in BMI during a 2-year period affected insulin resistance during school years. Considering the significant increase in overweight in this age group, special attention should be paid to monitoring increases in BMI in children from the Brazilian Amazon.

\section{Key words: Children: BMI gain: Insulin resistance: Brazilian Amazon}

Obesity, diabetes and high blood pressure are among the most significant features of the cardiometabolic disease and risk factor epidemic at the beginning of the twenty-first century $^{(1)}$. Analyses carried out using population-based health surveys highlight the importance of investigating determinants in developing countries, given the critical shift of the mortality burden of non-communicable diseases from developed regions worldwide because of a broad epidemiological transition ${ }^{(1,2)}$.

There is evidence of an association between growth and weight in early life and metabolically compromised parameters. Weight status and visceral adipose tissue have been shown to be associated with insulin resistance since school years in recent cross-sectional studies ${ }^{(3,4)}$. In addition, data from five prospective birth cohort studies carried out in Brazil, Guatemala, India, the Philippines and South Africa indicate a higher likelihood of overweight and elevated blood pressure among young adults because of a faster relative weight gain after the age of 2 years ${ }^{(5)}$. These studies also indicate that a faster weight gain after 4 years of age is positively associated with glucose intolerance. Insulin resistance in adulthood has been reported to be associated with weight gain from birth to adulthood in India, the Philippines and South Africa ${ }^{(6)}$.

Determinants of such metabolic parameters during childhood have not been explored very extensively, particularly in developing regions, where there is still a lower prevalence of overweight and obesity in the population. In view of the social and health inequalities related to non-communicable diseases, which are greatest among the poor ${ }^{(7)}$, monitoring these parameters could help provide possible interventions before adulthood and optimise healthier outcomes. Therefore, a population-based prospective study was carried out in the Brazilian Amazon to assess the impact of weight gain

Abbreviations: HDI, Human Development Index; HOMA-IR, homeostasis model assessment index of insulin resistance.

*Corresponding author: M. A. Cardoso, fax +55 113061 7705, email marlyac@usp.br 
on glucose and insulin concentrations, insulin resistance, and systolic and diastolic blood pressure ascertained during school years.

\section{Experimental methods}

\section{Study population}

This longitudinal study was conducted in Acrelândia, a frontier town located $112 \mathrm{~km}$ from Rio Branco, the capital of the State of Acre in the Western Brazilian Amazon region. By 2007, the town had 11520 inhabitants at baseline, of which $44 \%$ resided in an urban area, comprising mainly migrants from Southeastern and Southern regions of Brazil engaged in commercial agriculture and cattle farming. According to the Human Development Index (HDI), a summary estimate of the dimensions of health, education and population income, Acrelândia exhibited very low human development in 2000 (HDI: 0.451). By 2010, the town had reached a medium human development level (HDI: 0.604), but, of note, the relative position occupied by Acrelândia by the HDI during that decade dropped from the 3904th to 4055th in a total of 5565 Brazilian municipalities ${ }^{(8)}$. An initial population-based cross-sectional survey of child health and nutrition enrolled a total of 1225 children aged $\leq 10$ years $(98.0 \%$ of those eligible for the study) ${ }^{(9)}$. A follow-up assessment was carried out in December 2009 and 909 children of those included at baseline $(74 \cdot 2 \%)$ were identified.

The present analyses focused on school-aged children who were $>4$ to $\leq 10$ years and had complete anthropometric information in 2007 ( $n$ 696; 96.0\% of those initially enrolled in this age group). In 2009, these children were invited for a clinical examination for pubertal development evaluation, blood pressure measurement and blood sample collection and also for updating their anthropometric data.

The present study was conducted according to the guidelines laid down in the Declaration of Helsinki, and all procedures involving human subjects were approved by the ethical review board of the School of Public Health, University of São Paulo, Brazil. Written informed consent was obtained from parents or guardians before enrolment.

\section{Field procedures and laboratory methods}

As has been described previously ${ }^{(9)}$, during baseline household interviews with each participant's mother or guardian, information on the child's sex, age, race/ethnicity, nutritional history and recent morbidity was collected. The presence of twelve household assets was determined to generate a wealth index, which was divided into quartiles ${ }^{(10)}$. Maternal characteristics and child's birth weight were recorded as continuous variables, and then they were classified into categories based on the frequency and/or conceptual/biological meaning. Thus, for maternal education, mothers who had completed up to elementary school ( $\leq 4$ years) were compared with those who had completed middle school (5-8 years) or high school or more ( $\geq 9$ years); for maternal age, $\leq 21,22-34$, and $\geq 35$ year age groups were used.
Birth weights were retrieved from child health cards, and children who were born with a low birth weight $(\leq 2500 \mathrm{~g})$ were examined in relation to children of intermediate (2500-3500 g) and higher (>3500 g) birth weights.

Children's anthropometric measurements were obtained directly by trained research assistants using standardised procedures and calibrated equipment in all study assessments and recorded in duplicate ${ }^{(11)}$. Weight was measured to the nearest $100 \mathrm{~g}$ using an electronic scale (Tanita model HS-302), and height was measured to the nearest mm using stadiometers (in 2007 with the Seca model 208 and in 2009 with the WCS (Cardiomed)). BMI was computed as weight (in $\mathrm{kg}$ ) divided by height (in $\mathrm{m}^{2}$ ) and was used to calculate BMI-for-age $Z$-scores using the WHO Child Growth Standards ${ }^{(12)}$ for children aged $\leq 5$ years and the WHO Growth Reference Data for children aged $>5$ years ${ }^{(13)}$, with the WHO AnthroPlus software. Children were classified as overweight when BMI-for-age $Z$-scores $>1^{(13)}$.

During clinical examinations in 2009, trained research assistants ascertained pubertal development according to the Tanner stages ${ }^{(14)}$ and measured blood pressure after $5 \mathrm{~min}$ of rest using an automatic digital device with appropriate cuff sizes. The mean of three measurements of systolic and diastolic blood pressure was used. A sample $(5 \mathrm{ml})$ of fasting venous blood was collected from the children and serum and plasma samples were shipped to São Paulo on dry ice and frozen at $-70^{\circ} \mathrm{C}$ until further analysis. Glucose concentrations were determined with the automatic enzymatic method using hexokinase. For children aged $\geq 10$ years, increased plasma glucose concentrations were defined as glucose concentrations $\geq 5.55 \mathrm{mmol} / \mathrm{l}^{(15)}$. Insulin concentrations were determined by fluoroimmunoassay, and hyperinsulinaemia was defined as fasting insulin concentrations $90 \mathrm{pmol} / 1$ or $120 \mathrm{pmol} / \mathrm{l}$ for prepubescent and pubescent children, respectively ${ }^{(16,17)}$. The homeostasis model assessment index of insulin resistance (HOMA-IR) was calculated as insulin $(\mathrm{pmol} / \mathrm{l}) \times$ glucose $(\mathrm{mmol} / \mathrm{l}) / 135^{(18)}$. Based on a populationbased study among US adolescents, participants with HOMA-IR values $>4.39$ were classified as insulin resistant ${ }^{(19)}$.

\section{Statistical analyses}

Outcomes of interest were the metabolic parameters ascertained among the school-aged children in 2009 (systolic and diastolic blood pressure, glucose concentrations, insulin concentrations, and HOMA-IR values). Main exposure was variation in weight gain, measured as differences in BMIfor-age $Z$-scores from 2007 to 2009 in this age group.

First, the general socio-economic, maternal and child characteristics were compared in each study assessment using the $\chi^{2}$ test for categorical variables and the paired $t$ test for continuous variables. Metabolic parameters were compared by Tanner stages in 2009 with $t$ test for normally distributed variables and with the Wilcoxon rank-sum test for non-normally distributed variables. Linear regression models were used to estimate the impact of variation in weight gain during follow-up on each of the metabolic parameters. All estimates were initially adjusted in crude 
models for baseline BMI-for-age $Z$-score and child's sex, age and race/ethnicity. Models for systolic and diastolic blood pressure were also adjusted for the child's height at the follow-up assessment. Finally, fully adjusted models for each metabolic parameter considered all covariates in the crude models with further control for baseline household wealth, child's birth weight and Tanner stage at the last assessment. Non-normally distributed variables were logtransformed before analyses in the regression models. $P$ values (two-tailed) are presented for all statistical tests. STATA 11.2 (StataCorp) was used for all analyses.

\section{Results}

Among the 696 children with complete anthropometric information and aged $>4$ years at baseline, 50.6\% were females and $86.1 \%$ were of mixed race. By 2007, the BMI-for-age
$Z$-score was positively associated with male sex $(P=0 \cdot 01)$, household wealth $(P=0 \cdot 04)$ and child's birth weight $(P<0 \cdot 001)$. The main characteristics across the study assessments are given in Table 1. During the follow-up from 2007 to 2009 in this age group, the mean variation in BMI-for-age $Z$-scores was equivalent to $0 \cdot 14$ (SD 0.53). Between the two assessments, there was a significant increase in the mean BMIfor-age $Z$-score from -0.24 (SD 0.99) to -0.05 (SD 1.13) $(P=0.01)$ and in the proportion of overweight children from $10 \cdot 1$ to $15 \cdot 8 \%(P=0 \cdot 003)$.

A total of 507 children with exposure information at baseline were evaluated in 2009. Of these, 411 had data on metabolic parameters after clinical examination. The median follow-up period was $2 \cdot 0$ years (range $1 \cdot 7-2 \cdot 6$ years). There was no difference in children lost to follow-up and children included in the analyses, except for mean age at baseline and sex distribution. Participants not included in the analyses

Table 1. Characteristics of the school-aged children with complete anthropometric information at each study assessment, Acrelândia, Brazil

(Number of participants and percentages; mean values and standard deviations)

\begin{tabular}{|c|c|c|c|c|c|}
\hline & \multicolumn{2}{|c|}{2007} & \multicolumn{2}{|c|}{2009} & \multirow[b]{2}{*}{$P^{*}$} \\
\hline & $n$ & $\%$ & $n$ & $\%$ & \\
\hline Total† & $696 \ddagger$ & & 507 & & \\
\hline Sex & & & & & 0.36 \\
\hline Female & 352 & $50 \cdot 6$ & 270 & $53 \cdot 2$ & \\
\hline Male & 344 & 49.4 & 237 & $46 \cdot 8$ & \\
\hline Age (years) & & & & & $<0.001$ \\
\hline Mean & \multicolumn{2}{|c|}{$7 \cdot 1$} & \multicolumn{2}{|c|}{9.1} & \\
\hline SD & \multicolumn{2}{|c|}{1.8} & \multicolumn{2}{|c|}{1.8} & \\
\hline Race/ethnicity & & & & & 0.90 \\
\hline White & 57 & 8.9 & 39 & 8.4 & \\
\hline Mixed race & 551 & $86 \cdot 1$ & 402 & $87 \cdot 0$ & \\
\hline Black & 32 & 5.0 & 21 & 4.6 & \\
\hline Household wealth index & & & & & 0.81 \\
\hline First quartile (lowest) & 156 & $22 \cdot 5$ & 104 & 20.5 & \\
\hline Second quartile & 191 & $27 \cdot 4$ & 140 & $27 \cdot 6$ & \\
\hline Third quartile & 178 & $25 \cdot 6$ & 129 & $25 \cdot 5$ & \\
\hline Fourth quartile (highest) & 170 & 24.5 & 134 & $26 \cdot 4$ & \\
\hline Maternal educational level (years) & & & & & 0.93 \\
\hline$\leq 4$ & 286 & $42 \cdot 4$ & 210 & 41.5 & \\
\hline $5-8$ & 200 & $29 \cdot 7$ & 150 & 29.6 & \\
\hline$\geq 9$ & 188 & $27 \cdot 9$ & 146 & 28.9 & \\
\hline Maternal age (years) & & & & & 0.73 \\
\hline$\leq 34$ & 502 & $72 \cdot 1$ & 361 & 71.2 & \\
\hline$\geq 35$ & 194 & $27 \cdot 9$ & 146 & 28.8 & \\
\hline Birth weight (g) & & & & & 0.64 \\
\hline$\leq 2500$ & 42 & $6 \cdot 7$ & 37 & $8 \cdot 0$ & \\
\hline $2501-3500$ & 372 & $59 \cdot 6$ & 266 & $57 \cdot 3$ & \\
\hline$>3500$ & 210 & 33.7 & 161 & 34.7 & \\
\hline BMI-for-age Z-score† & & & & & $<0.001$ \\
\hline Mean & & & & & \\
\hline $\mathrm{SD}$ & & & & & \\
\hline Overweight§ & 70 & $10 \cdot 1$ & 80 & $15 \cdot 8$ & 0.003 \\
\hline Height-for-age Z-score $†$ & & & & & $<0.001$ \\
\hline Mean & & & & & \\
\hline SD & & & & & \\
\hline Stunting\|l & 22 & $3 \cdot 2$ & 18 & 3.6 & 0.71 \\
\hline
\end{tabular}

* $P$ values were calculated using the $\chi^{2}$ test for categorical variables and the paired $t$ test for continuous variables. †BMI-for-age and height-for-age $Z$-scores were calculated according to the WHO growth references.

$¥$ Total may be different from 696 because of missing data.

$\S$ Overweight was defined as a BMI-for-age Z-score above 1

II Stunting was defined as a height-for-age $Z$-score below -2 . 
Table 2. Distribution of the metabolic parameters of the school-aged children according to Tanner stage, Acrelândia, Brazil, 2009

(Mean values and standard deviations for normally distributed variables; medians and interquartile ranges (IQR) for non-normally distributed variables)

\begin{tabular}{|c|c|c|c|c|c|c|c|}
\hline & \multicolumn{7}{|c|}{ Tanner stages } \\
\hline & \multicolumn{3}{|c|}{ Prepubertal } & \multicolumn{3}{|c|}{ Pubertal } & \multirow[b]{2}{*}{$P^{*}$} \\
\hline & $n$ & Mean & SD & $n$ & Mean & SD & \\
\hline Glucose (mmol/l) & 235 & 5.03 & 0.47 & 145 & $5 \cdot 16$ & 0.40 & 0.006 \\
\hline Insulin (pmol//) & 223 & & & 131 & & & $<0.001$ \\
\hline Median & & 29.4 & & & $47 \cdot 4$ & & \\
\hline IQR & & $20 \cdot 4,39.6$ & & & $30 \cdot 0,75 \cdot 6$ & & \\
\hline HOMA-IR & 218 & & & 131 & & & $<0.001$ \\
\hline Median & & 1.09 & & & $1 \cdot 71$ & & \\
\hline IQR & & $0.74,1.47$ & & & $1 \cdot 15,2 \cdot 92$ & & \\
\hline Systolic blood pressure (mmHg) & 242 & $100 \cdot 1$ & $8 \cdot 6$ & 148 & 98.8 & $10 \cdot 0$ & 0.16 \\
\hline Diastolic blood pressure $(\mathrm{mmHg})$ & 242 & $62 \cdot 4$ & $6 \cdot 3$ & 148 & $62 \cdot 6$ & $7 \cdot 0$ & 0.75 \\
\hline
\end{tabular}

were slightly younger at baseline (difference 1.01 years, $95 \%$ CI $0.75,1.26$ years), and the follow-up rate was $3.7 \%$ higher among the females $(P=0 \cdot 02)$.

The metabolic parameters of the school-aged children were compared according to Tanner stages in 2009 (Table 2). Pubescent participants had higher glucose concentrations, insulin concentrations and HOMA-IR values. Increased plasma glucose concentrations, defined as glucose concentrations $\geq 5.55 \mathrm{mmol} / 1$ for children aged $\geq 10$ years ( $n$ 164), were detected in $20 \cdot 1 \%$ of the children. Among prepubescent ( $n$ 223) and pubescent ( $n$ 131) participants altogether, hyperinsulinaemia was observed in $5.0 \%$ of the children. In addition, $5 \cdot 1 \%$ ( $n$ 19) of all children with available data were considered insulin resistant, with HOMA-IR values $>4.39$. Among the insulin-resistant participants, fifteen were girls and ten were classified as pubescent. Also, twelve of these children were overweight (BMI-for-age $Z$-score $>1$ ).
Weight gain from 2007 to 2009 measured as the difference in BMI-for-age $Z$-scores was associated with higher insulin concentrations and HOMA-IR values among the school-aged children, after adjustment for sex, age, race/ethnicity, baseline household wealth, birth weight and Tanner stage (Table 3). For each unit of BMI-for-age $Z$-score, insulin concentrations and HOMA-IR values increased by 8.58 (95\% CI 7.68, 9.60) $\mathrm{pmol} / \mathrm{l}$ and 1.47 (95\% CI 1.30, 1.66), respectively. No association with either systolic or diastolic blood pressure values was found.

\section{Discussion}

In the present study, weight gain during follow-up among the school-aged children living in the Brazilian Amazon was found to be related to higher insulin concentrations and insulin resistance values, as measured by HOMA-IR. Also,

Table 3. Linear regression coefficients for the association of weight gain (in units of BMI-for-age Z-score) with metabolic parameters among the school-aged children, Acrelândia, Brazil, 2007-9 ( $\beta$-Coefficients and $95 \%$ confidence intervals)

\begin{tabular}{|c|c|c|c|c|c|c|c|}
\hline & \multirow[b]{3}{*}{$n$} & \multicolumn{6}{|c|}{ Weight gain BMI-for-age Z-score difference* } \\
\hline & & \multicolumn{3}{|c|}{ Crude† } & \multicolumn{3}{|c|}{ Adjusted $\ddagger$} \\
\hline & & $\beta$ & $95 \% \mathrm{Cl}$ & $r^{2}$ & $\beta$ & $95 \% \mathrm{Cl}$ & $r^{2}$ \\
\hline Glucose (mmol/l) & 402 & 0.07 & $-0.01,0.16$ & 0.01 & 0.07 & $-0.01,0.16$ & 0.12 \\
\hline Insulin (pmol/l) & 376 & $8 \cdot 82$ & $7 \cdot 86,9 \cdot 94$ & 0.11 & $8 \cdot 58$ & $7 \cdot 68,9 \cdot 60$ & 0.42 \\
\hline HOMA-IR & 371 & 1.52 & $1 \cdot 35,1 \cdot 71$ & 0.11 & 1.47 & $1 \cdot 30,1 \cdot 66$ & 0.41 \\
\hline Systolic blood pressure (mmHg) & 411 & -0.41 & $-2 \cdot 17,1 \cdot 35$ & 0.01 & -0.69 & $-2.48,1.09$ & 0.06 \\
\hline Diastolic blood pressure (mmHg) & 411 & 0.06 & $-1 \cdot 20,1 \cdot 32$ & 0.01 & -0.10 & $-1 \cdot 38,1 \cdot 18$ & 0.06 \\
\hline \multicolumn{8}{|c|}{$\begin{array}{l}\text { HOMA-IR, homeostasis model assessment index of insulin resistance. } \\
\text { *BMI-for-age Z-scores were calculated according to the WHO growth references. } \\
\text { † Linear regression models for crude estimates included the difference in BMI-for-age Z-scores for the } 2007-9 \text { period, the baseline } \\
\text { BMI-for-age Z-score value, and child's sex, age, and race/ethnicity. Models for systolic and diastolic blood pressure were additionally } \\
\text { adjusted for the child's height at the follow-up assessment. Insulin concentration and HOMA-IR values were log-transformed before } \\
\text { analysis and estimates reported in this table were then exponentiated back to the original scale. }\end{array}$} \\
\hline \multicolumn{8}{|c|}{$\begin{array}{l}\text { † Fully adjusted estimates were controlled for the baseline BMl-for-age } Z \text {-score value, child's sex, age, and race/ethnicity, baseline } \\
\text { household wealth, and child's birth weight and Tanner stage at the last assessment. Models for systolic and diastolic blood pressure } \\
\text { were additionally adjusted for the child's height at the follow-up assessment. Insulin concentration and HOMA-IR values were } \\
\text { log-transformed before analysis and estimates reported in this table were then exponentiated back to the original scale. }\end{array}$} \\
\hline
\end{tabular}


there was a significant increase in overweight in this age group during the study period (2007-9).

As expected, the results of the present study confirm the physiological increase in insulin resistance during pubertal development ${ }^{(17)}$, as evidenced by the significantly higher insulin concentrations and HOMA-IR values among pubescent participants. Mean HOMA-IR values and occurrence of hyperinsulinaemia were lower during school years in Acrelândia children when compared with that found in other investigations in developing areas. A population-based study with 6132 healthy children and adolescents in Mexico ${ }^{(20)}$ has found that the absolute mean HOMA-IR value is equal to $2 \cdot 89$ (SD 0.70). Nonetheless, we did observe a significant influence of weight gain on insulin resistance, after adjustment for the child's sex, age and Tanner stage, among other covariates. In line with these findings, weight gain during childhood, and more specifically fat mass as measured with dual-energy X-ray absorptiometry, has been found to be associated with higher insulin resistance among 238 children aged 7-13 years in the $\mathrm{UK}^{(21)}$. Similar associations have also been reported in developing areas with regard to insulin resistance as the outcome among adults in longitudinal investigations. Higher increases in BMI between childhood or adolescence and adulthood have been reported to be positively associated with higher HOMA-IR values in rural communities in India ${ }^{(22)}$. Conditional weight gains as early as from birth to 2 years of age have been shown to be associated with insulin resistance during young adulthood in three other birth cohort studies conducted in developing countries ${ }^{(6)}$.

As insulin resistance has a key role in metabolic changes and is a risk factor for the development of type 2 diabetes as well as is closely related to BMI from an early age ${ }^{(23)}$, it is important to note that the longitudinal impact of weight gain observed in the present study was accompanied by a significant increase in overweight during a relatively short follow-up period, from $10 \cdot 1$ to $15 \cdot 8 \%$ in 2 years. Although these values may not be extremely high, the increasing prevalence of overweight and obesity worldwide ${ }^{(24)}$ is a public health concern. In this sense, the results of the present study shed light on the dual burden of disease affecting children in rapidly changing environments, which commonly lack material and structural resources, but progressively promote the development of chronic disease risk and, therefore, call for action in preventing both under- and overnutrition in a timely manner ${ }^{(25,26)}$.

There are some limitations to the present study. Although the overall follow-up rate was high, there were differences between the children included and those not included in the analyses with regard to baseline age and sex, and the potential implications are difficult to assess. In addition, there was only one measurement available for the metabolic outcomes studied, but assessment of such parameters was done during earlier stages of life when compared with other prospective investigations. Although several study cohorts have found evidence for a role of growth in blood pressure in adult$\operatorname{hood}^{(5,27-29)}$, associations of weight gain with systolic and diastolic blood pressure during school years could not be verified in the present study, possibly because of the shorter follow-up period.

The present study also has several strengths, including its longitudinal, population-based design, the ability to control for pubertal development, and the use of direct and standardised anthropometric measurements expressed as WHO Z-scores.

In conclusion, we found evidence for an impact of weight gain on insulin resistance after only a 2-year period during school years. Considering the significant increase in overweight in this age group, special attention should be paid to monitoring increases in BMI in children from the Brazilian Amazon.

\section{Acknowledgements}

The authors are grateful to all families and health professionals in Acrelândia as well as their research team members for their collaboration in the present study.

The present study was funded by the Brazilian National Counsel of Technological and Scientific Development, CNPq (grant no. 551359/2001-3, 502937/2003-3, 307728/2006-4, and 470573/2007-4) and the São Paulo Research Foundation, FAPESP (grant no. 2007/53042-1). B. H. L. received PhD scholarships from the FAPESP (grant no. 2008/57796-3) and the Organization of American States (BR Self Grad 2010/11, ID 20100656). The views expressed in the present article are those of the authors and not necessarily those of any funding agencies or others whose support is acknowledged. The funders had no role in the design and analysis of the study or in the writing of this article.

The authors' contributions are as follows: B. H. L. contributed to the study design and data collection, conducted data analyses, participated in data interpretation, wrote the initial draft of the article, and was involved in the review of the article; S. G. A. G. participated in data collection and interpretation and was involved in the review of the article; M. A. C. implemented and supervised all study protocols, was responsible for project management, participated in data interpretation, and was involved in the review of the article.

None of the authors has any conflicts of interest to declare.

\section{References}

1. The Global Burden of Metabolic Risk Factors for Chronic Diseases Collaboration (2014) Cardiovascular disease, chronic kidney disease, and diabetes mortality burden of cardiometabolic risk factors from 1980 to 2010: a comparative risk assessment. Lancet Diabetes Endocrinol 2, 634-647.

2. Alwan A, MacLean DR, Riley LM, et al. (2010) Monitoring and surveillance of chronic non-communicable diseases: progress and capacity in high-burden countries. Lancet 376, 1861-1868.

3. Burrows T, Collins CE \& Garg ML (2011) Omega-3 index, obesity and insulin resistance in children. Int $J$ Pediatr Obes 6, e532-e 539 .

4. Bosch TA, Dengel DR, Kelly AS, et al. (2014) Visceral adipose tissue measured by DXA correlates with measurement by CT and is associated with cardiometabolic risk factors 
in children. Pediatr Obes (Epublication ahead of print version 3 July 2014).

5. Adair LS, Fall CHD, Osmond C, et al. (2013) Associations of linear growth and relative weight gain during early life with adult health and human capital in countries of low and middle income: findings from five birth cohort studies. Lancet 382, 525-534.

6. Norris SA, Osmond C, Gigante D, et al. (2012) Size at birth, weight gain in infancy and childhood, and adult diabetes risk in five low- or middle-income country birth cohorts. Diabetes Care 35, 72-79.

7. Alleyne G, Binagwaho A, Haines A, et al. (2013) Embedding non-communicable diseases in the post-2015 development agenda. Lancet 381, 566-574.

8. United Nations Development Programme (UNDP) (2013) HDI ranking for municipalities in Brazil 2013: UNDP Brazil. http://www.pnud.org.br/atlas/ranking/IDH-Globlal-2013.aspx? indiceAccordion=1\&li=li_Ranking2013 (accessed July 2014).

9. Cardoso MA, Scopel KKG, Muniz PT, et al. (2012) Underlying factors associated with anemia in Amazonian children: a population-based, cross-sectional study. PLOS ONE 7, e36341.

10. Filmer D \& Pritchett LH (2001) Estimating wealth effects without expenditure data- or tears: an application to educational enrollments in states of India. Demography $\mathbf{3 8}$, $115-132$

11. Lohman TG, Roche AF \& Martorell R (1988) Anthropometric Standardization Reference Manual. Champaign, IL: Human Kinetics Books.

12. World Health Organization (WHO) (2006) WHO child growth standards based on length/height, weight and age. Acta Paediatr Suppl 450, S76-S85.

13. de Onis M, Onyango AW, Borghi E, et al. (2007) Development of a WHO growth reference for school-aged children and adolescents. Bull World Health Organ 85, 660-667.

14. Tanner JM (1962) Growth of Adolescents. Oxford, UK: Blackwell Scientific.

15. Zimmet P, Alberti G, Kaufman F, et al. (2007) The metabolic syndrome in children and adolescents. Lancet 369 , 2059-2061.

16. Ten S \& Maclaren N (1993) Insulin resistance in children. J Clin Endocrinol Metab 76, 44-48.

17. Goran MI \& Gower BA (2001) Longitudinal study on pubertal insulin resistance. Diabetes 50, 2444-2450.

\section{Appendix}

The members of the ACTION (ACre nutriTION) Study Team are as follows: Pascoal Torres Muniz, Orivaldo Florencio Souza, Cristieli Sergio de Menezes Oliveira, and Thiago Santos de Araujo (Department of Health Sciences, Federal University of Acre, Rio Branco, Brazil); Suely de Godoy Agostinho Gimeno, Luciana Yuki Tomita (Department of Preventive Medicine, Federal University of São Paulo, São Paulo, Brazil); Marcelo Urbano Ferreira (Institute of Biomedical Sciences, University
18. Matthews DR, Hosker JP, Rudenski AS, et al. (1985) Homeostasis model assessment: insulin resistance and cell function from fasting plasma glucose and insulin concentrations in man. Diabetologia 28, 412-419.

19. Lee JM, Okumura MJ, Davis MM, et al. (2006) Prevalence and determinants of insulin resistance among U.S. adolescents. Diabetes Care 29, 2427-2432.

20. Aradillas-García C, Rodríguez-Morán M, Garay-Sevilla ME, et al. (2012) Distribution of the homeostasis model assessment of insulin resistance in Mexican children and adolescents. Eur J Endocrinol 166, 301-306.

21. Hosking J, Metcalf BS, Jeffery AN, et al. (2011) Direction of causality between body fat and insulin resistance in children - a longitudinal study (EarlyBird 51). Int J Pediatr Obes 6, 428-433.

22. Raghupathy P, Antonisamy B, Geethanjali FS, et al. (2010) Glucose tolerance, insulin resistance and insulin secretion in young south Indian adults; relationships to parental size, neonatal size and childhood body mass index. Diabetes Res Clin Pract 87, 283-292.

23. Cree-Green M, Triolo TM \& Nadeau K (2013) Etiology of insulin resistance in youth with type 2 diabetes. Curr Diab Rep 13, 81-88.

24. Swinburn BA, Sacks G, Hall KD, et al. (2011) The global obesity pandemic: shaped by global drivers and local environments. Lancet 378, 804-814.

25. Black RE, Victora CG, Bhutta ZA, et al. (2013) Maternal and child undernutrition and overweight in low-income and middle-income countries. Lancet 382, 427-451.

26. Navarro JI, Sigulem DM, Ferraro AA, et al. (2013) The double task of preventing malnutrition and overweight: a quasiexperimental community-based trial. BMC Public Health 13, 212.

27. Kwok MK, Freeman G, Lin SL, et al. (2013) Simulated growth trajectories and blood pressure in adolescence: Hong Kong's Chinese Birth Cohort. J Hypertens 31, 1785-1797.

28. Normia J, Laitinen K, Isolauri E, et al. (2013) Impact of intrauterine and post-natal nutritional determinants on blood pressure at 4 years of age. J Hum Nutr Diet 26, $544-552$.

29. de Hoog MLA, van Ejsden M, Stronks K, et al. (2012) Association between body size and blood pressure in children from different ethnic origins. Cardiovasc Diabetol 11, 136.

of São Paulo, São Paulo, Brazil); Kézia K. G. Scopel (Department of Parasitology, Immunology and Microbiology, Federal University of Juiz de Fora, Juiz de Fora, Brazil); Barbara Hatzlhoffer Lourenço, Pablo Secato Fontoura, Fernanda Serra Granado, Fernanda Cobayashi, Rosangela Aparecida Augusto, and Marly Augusto Cardoso (Department of Nutrition, School of Public Health, University of São Paulo, São Paulo, Brazil). 